\title{
1p21.3 microdeletion syndrome
}

INSERM

\section{Source}

INSERM. (1999). Orphanet: an online rare disease and orphan drug data base. 1p21.3 microdeletion syndrome. ORPHA:293948

1 p21.3 microdeletion syndrome is an extremely rare chromosomal anomaly characterized by severe speech and language delay, intellectual deficiency, autism spectrum disorder(see this term). 